\title{
COUPE DE GRACE: AUTOPSY IN COVID-19 PANDEMIC
}

As the media informed the spread of a highly transmissible disease, our medical community faced the disappearance of a languishing ancient tool. Traditionally helping to explain unexplainable death, educate, audit, warn relatives, or contacts; autopsies vanished in a reassigned COVID-19 teaching hospital (Fig. 1).

Autopsies engendered pathology to clarify the causes of sign and symptoms on human death. This medical specialty evolved through centuries into subdisciplines, bringing pathologists to the forefront of medical care. Perceived as modern and more rewarding than postmortem anatomic pathology, these new pathology fields have grown and crowded the agenda, providing extensive, detailed information that translate to reliable diagnoses. The astonishing development of the pathology specialty could have been the happy ending to human disease, if not for the fallout faced these days. After $>378,000$ COVID-19-related deaths worldwide, only 31 complete autopsies have been reported $^{1-3}$.

Not only medicine without autopsies is the theme played after SARS-CoV-2. The situation resembles an old classroom exercise: "imagine medicine without pathology," a playful strategy of "old-fashioned" teachers. Reconverted hospitals for COVID-19 care, suddenly lack specimens to diagnose and teach pathology residents. Today, care and treatment decisions are made in a different turf where pathological

Figure 1. Death and autopsy rate in a teaching hospital in Mexico City. Protracted decline (19\%-2\%) with random peaks is observed from 2000 to 2019. Because of the lack of biosecurity level 3 postmortem areas, no autopsies have been performed this year.

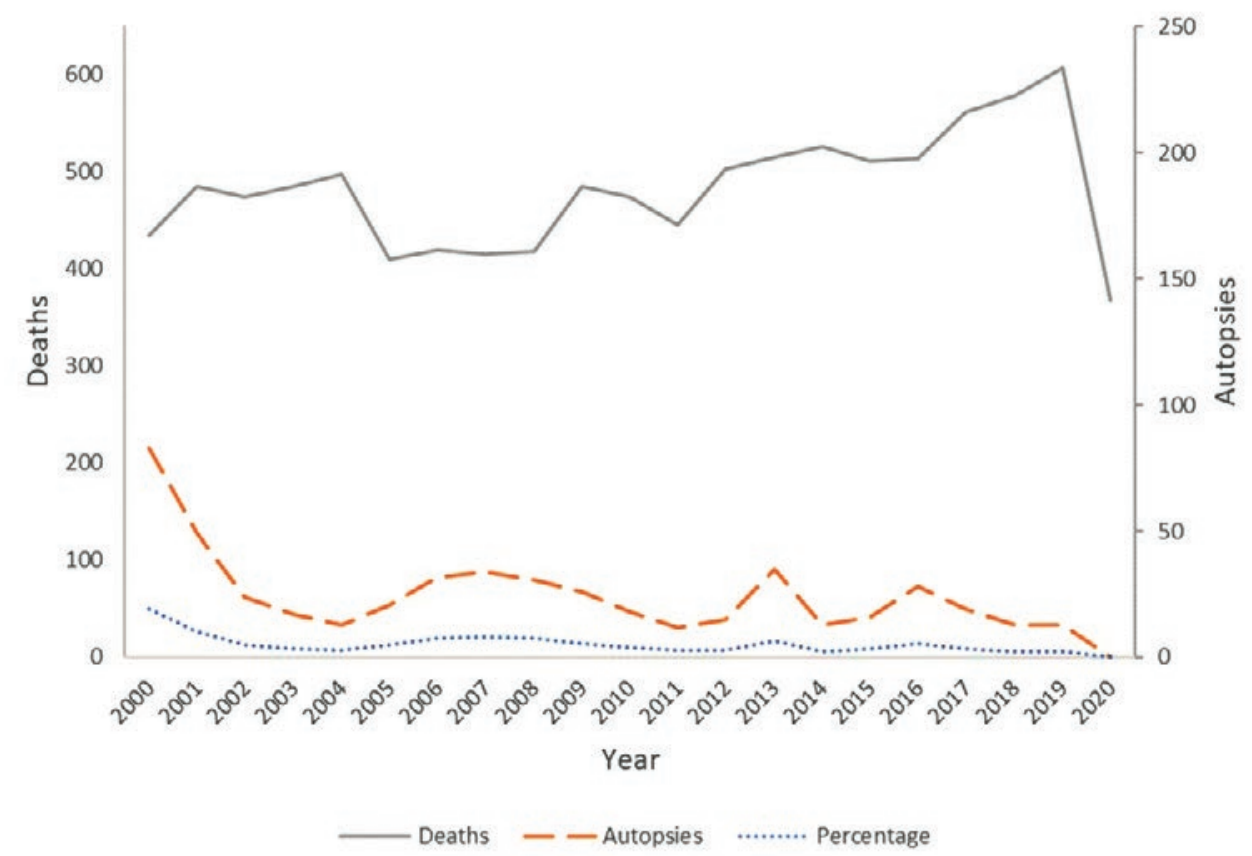

0034-8376 / (C) 2020 Revista de Investigación Clínica. Published by Permanyer. This is an open access article under the CC BY-NC-ND license (http://creativecommons.org/licenses/by-nc-nd/4.0/). 
findings are dismissed or inexistent, and the only real concern is safely handle and deliver the deceased to their families.

Notwithstanding so many deaths from COVID-19, some clinicians confess their blindness and request for anatomoclinical correlations. To address this need, pathologists once personal protection equipment obtained, look for safe facilities to perform autopsies, but a glimpse of reality shows none: most autopsy rooms are insecure/obsolete ${ }^{4}$. Every physician, hospital, and health administrator should remember that once performed, autopsies unveil relevant unsuspected findings in more than 2 out of 10 hospitalized patients, even when deaths occur in high-tech intensive care units ${ }^{5}$.

With the storm of proposed hypothesis awaiting for confirmation on SARS-CoV-2/human interaction, complete medical autopsies are mandatory to sample and preserve specimens for in-depth research in all biomedical fields. For medical care, autopsies represent certainty on cause of death, identification, and contribution of comorbidities and, a tool to identify if treatment results are consistent with the objectives of clinical research protocols. It is a necessary procedure for fine tuning and teaching medicine in the postCOVID-19 era.

Pathology leaders need to embrace new biosafety standards in the short term, quickly invest, and reorganize autopsy and grossing areas to deal with this and other emerging transmissible agents. This is a difficult endeavor since sanitary and economic crises are found together in hospitals. In the meantime, while waiting for the call of the on-duty stretcherbearer, we share our thoughts and vision of a new perspective in our laboratories and role.

\section{REFERENCES}

1. Barton LM, Duval EJ, Stroberg E, Ghosh S, Mukhopadhyay S. Covid-19 autopsies, Oklahoma, USA. Am J Clin Pathol. 2020; $153 ; 725-33$

2. Wichmann D, Sperhake JP, Lügehetmann M, Steurer S, Edler C, Gross $\mathrm{O}$, et al. Autopsy findings and venous thromboembolism in patients with COVID-19: a prospective cohort study. Ann Intern Med. 2020;M20-2003;[Epub ahead of print].

3. Menter T, Haslbauer JD, Nienhold R, Savic S, Hopfer H, Deigendesch $\mathrm{N}$, et al. Post-mortem examination of COVID-19 patients

reveals diffuse alveolar damage with severe capillary congestion and variegated findings of lungs and other organs suggesting vascular dysfunction. Histopathology. 2020; [Epub ahead of print].

4. Fusco FM, Scappaticci L, Schilling S, De laco G, Brouqui P, Maltezou HC, et al. A 2009 cross-sectional survey of procedures for post-mortem management of highly infectious disease patients in 48 isolation facilities in 16 countries: data from EuroNHID. Infection. 2016;44:57-64.

5. Roulson J, Benbow EW, Hasleton PS. Discepancies between clinical and autopsy diagnosis and the value of post mortem histology; a meta-analysis and review. Histopathology. 2005; 47:551-9.

\section{JaVier Rios-Valencia and Armando Gamboa-DomíngUez*}

Department of Pathology, Instituto Nacional de Ciencias Médicas y Nutrición Salvador Zubirán, Mexico City, Mexico

*Corresponding author:

Armando Gamboa-Dominguez

E-mail: armando.gamboad@incmnsz.mx
Received for publication: 04-06-2020

Approved for publication: 30-06-2020

DOI: $10.24875 / R I C .20000262$ 